\title{
Lymphovascular Invasion 2
}

National Cancer Institute

\section{Source}

National Cancer Institute. Lymphovascular Invasion 2. NCI Thesaurus. Code C147094.

Lymphatic and small vessel invasion only. (AJCC 8th ed.) 